\title{
A construção com verbos de cognição no português brasileiro: um estudo preliminar
}

Sheyla Patrícia Trindade da Silva Costa ${ }^{a}$ Maria Angélica Furtado da Cunha ${ }^{b}$

\begin{abstract}
Resumo
Este artigo apresenta uma análise preliminar acerca da estrutura argumental com verbos de cognição no português brasileiro. Os dados analisados foram coletados em uma entrevista sociolinguística, cujo informante é um homem representante da fala de $\mathrm{Natal} / \mathrm{RN}$, de 50 anos, com nível de escolaridade de Ensino Fundamental II. Os resultados obtidos demonstram que a construção de estrutura argumental prototípica para os verbos de cognição corresponde a um subesquema da construção transitiva prototípica e é instanciada na grande maioria dos construtos, os quais remetem a subesquemas mais específicos, a depender do item linguístico que assume a função de objeto direto. O suporte teórico adotado é o da Linguística Funcional Centrada no Uso (LFCU), um modelo teórico-metodológico que absorve princípios, processos e categorias integrantes da linguística funcional norte-americana e da linguística cognitiva.
\end{abstract}

Palavras-chave: Estrutura argumental. Verbos de cognição. Linguística Funcional Centrada no Uso. 


\section{Introdução}

Os verbos de cognição correspondem a um dos subtipos de processos mentais, conforme exposto em Halliday (1985) e Halliday e Matthiessen (2004). Esses processos são caracterizados por esses autores como processos de sentir pensar e ver, ou seja, não correspondem a ações do mundo material, mas referem-se a atividades que se processam mentalmente. Como diz Souza (2006, p. 461), "os processos mentais lidam com a apreciação humana do mundo. Através de sua análise, é possível detectar que crenças, valores e desejos estão representados em um dado texto" (grifo da autora). Ou ainda, nas palavras de Furtado da Cunha e Souza (2011, p. 73), "orações, ou sentenças, com processos mentais respondem à pergunta o que você sente, pensa ou sabe sobre $x$ ? Com verbos como esses, não tratamos de ações, mas de reações mentais, de pensamentos, sentimentos e percepções" (grifo das autoras).

Halliday (1985) divide os processos mentais em três subtipos: os processos mentais de percepção, relacionados à observação ou à sensação de fenômenos, expressos por verbos como sentir, ouvir, ver, degustar e cheirar; os processos mentais de afeição, relacionados aos sentimentos e expressos por verbos como amar e gostar; e os processos mentais de cognição, relacionados à decisão, à consideração ou à crença, à memória, à compreensão e ao planejamento, expressos por verbos como decidir, considerar, achar, supor, acreditar, imaginar, lembrar, esquecer, saber, entender, perceber, compreender, pensar e planejar. Em Halliday e Matthiessen (2004), um quarto subtipo é acrescentado a essa divisão: o dos processos mentais de desejo, expressos por verbos como querer e desejar.

Este artigo se debruça especificamente sobre os verbos do subtipo de cognição, os quais, assim como todos os demais verbos que indicam processos mentais, implicam a existência de dois participantes: o experienciador, prototipicamente humano, com volição e consciência, em cuja mente se realiza o processo; e o fenômeno, aquilo que, no caso dos verbos de cognição, é decidido, considerado, lembrado, esquecido, compreendido ou planejado pelo experienciador. Seres destituídos de consciência podem participar como experienciadores, mas apenas em cenas metaforicamente construídas, nas quais aparecem personificados como seres conscientes (GOUVEIA, 2009). 
O objetivo geral deste trabalho é identificar a estrutura argumental prototípica para os verbos de cognição e suas instanciações nos dados analisados. Os objetivos específicos são: listar os verbos que indicam eventos de cognição nos dados analisados; descrever a estrutura argumental prototípica, em termos de frequência de ocorrência, para expressar um evento de cognição; apontar os padrões de estrutura argumental, além da construção prototípica, que possam codificar um evento desse tipo; analisar os fatores cognitivos e interacionais que levam ao uso de um determinado padrão de estrutura argumental em detrimento de outro(s); caracterizar morfossintática e semanticamente os argumentos que se relacionam com o verbo de cognição.

Na primeira seção, dedicada à fundamentação teórica, apresenta-se sinteticamente o paradigma da Linguística Funcional Centrada no Uso (LFCU), assim como o estudo da transitividade verbal nesse contexto, seguido de breve apresentação da Gramática de Construções (GOLDBERG, 1995; TRAUGOTT e TROUSDALE, 2013) e do conceito de estrutura argumental. Na segunda seção, explica-se como os dados utilizados neste artigo foram coletados e, na terceira, procede-se à apresentação dos resultados e à posterior análise. Por último, as considerações finais, que visam a responder ao objetivo geral e a cada um dos objetivos específicos delimitados.

\section{Fundamentação teórica}

\subsection{A Linguística Cognitivo-Funcional ou Linguística Funcional Centrada no Uso}

A expressão "linguística cognitiva" já era conhecida na década de 1960, mas ganhou relevo a partir dos anos 1980, com George Lakoff, Ronald Langacker, Leonard Talmy, Charles Fillmore e Gilles Fauconnier, os quais, antes adeptos do gerativismo, passaram a se dedicar a estudos linguísticos que analisassem as relações entre sintaxe e semântica. Ao contrário do que ocorre no gerativismo, que adota uma concepção modular, com a primazia do módulo sintático sobre os demais, o cognitivismo assume a interação entre os módulos linguísticos, sobretudo entre a forma e o significado, bem como a existência de princípios cognitivos gerais, não exclusivos da 
linguagem, mas que também atuam sobre ela e, a partir disso, assume também uma perspectiva de análise baseada no uso.

[...] a Linguística Cognitiva defende que a relação entre palavra e mundo é mediada pela cognição. Assim, o significado deixa de ser um reflexo direto do mundo, e passa a ser visto como uma construção cognitiva através da qual o mundo é apreendido e experienciado. Sob essa perspectiva, as palavras não contêm significados, mas orientam a construção do sentido. (FERRARI, 2011, p. 14)

São processos essenciais no âmbito da linguística cognitiva a categorização, a metáfora e a metonímia, os quais serão explicitados adiante.

A linguística funcional da vertente norte-americana, por sua vez, tem como principais representantes Talmy Givón, Paul Hopper, Joan Bybee, Sandra Thompson e Wallace Chafe, entre outros, e traz a ideia central de que a língua é usada, sobretudo, para satisfazer necessidades comunicativas, por isso é um código parcialmente arbitrário, maleável, sujeito às pressões do uso, ou seja, é um sistema adaptativo complexo, composto por padrões mais ou menos regulares, mas também por outros que se encontram em emergência, sempre visando a atender necessidades cognitivas e/ou intercomunicativas dos falantes (BYBEE, 2010).

A gramática é concebida como natural e dinâmica, pois se encontra em contínuo processo de variação e mudança para atender a necessidades cognitivas e/ou interacionais de seus usuários. Sendo assim, a gramática apresenta categorias morfossintáticas rotinizadas, com padrões funcionais mais regulares, e formas que se encontram em processo de variação e mudança, sempre motivado por fatores cognitivo-interacionais (FORD et al., 2003).

Entre os processos de variação, há os que se caracterizam como fenômenos de gramaticalização, os quais podem se manifestar tanto sincrônica quanto diacronicamente, seja na função (discursivo-pragmática ou semântico-cognitiva) ou na forma (nos níveis morfossintático e/ou fonológico) (LEHMANN, 1982; GIVÓN, 1995; HOPPER; TRAUGOTT, 2003; FURTADO DA CUNHA; BISPO; SILVA, 2013). O processo de gramaticalização se inicia quando novas formas ou novas funções para velhas formas surgem como variantes usadas ocasionalmente, visando a uma maior eficácia comunicativa. 
Se essa variante se tornar usual na comunidade linguística, diz-se que ela foi gramaticalizada, o que significa que uma nova regra emergiu do discurso para a gramática. Como processo, a gramaticalização não ocorre de forma instantânea, mas gradual, o que implica que as formas variantes coexistem, por um longo período de tempo, até que, pelo menos na maioria das vezes, o novo uso possa substituir inteiramente o mais antigo (HOPPER e TRAUGOTT, 2003).

Considera-se, então, que há uma simbiose entre discurso e gramática (FURTADO DA CUNHA; BISPO; SILVA, 2013): enquanto a gramática molda o discurso, pois fornece as convenções básicas para que a comunicação, no uso da língua, ocorra de maneira coerente, é do uso real desse código, portanto do discurso, que tais convenções emergem. O discurso e a gramática são, pois, determinados um pelo outro reciprocamente, e a gramática, então, nunca se estabiliza completamente, permanece num constante fazer-se, é uma gramática emergente (HOPPER, 1998).

A adoção dessas concepções de língua e de gramática implica assumir que a investigação dos fenômenos linguísticos deve se basear no discurso, ou seja, no "conjunto de estratégias criativas empregadas pelo falante para organizar funcionalmente seu texto para um determinado ouvinte em uma determinada situação de comunicação" (FURTADO DA CUNHA; SOUZA, 2011, p.23). A principal hipótese é a de que a forma da língua deve refletir, em alguma medida, a função que exerce, e nisso consiste o princípio da iconicidade (HAIMAN, 1985; GIVÓN, 1985).

Segundo Givón (1984), o princípio da iconicidade envolve três subprincípios: o da quantidade, o da proximidade e o da ordenação linear. O subprincípio da quantidade diz que quanto mais complexa for a mensagem, maior será a quantidade de forma necessária para sua codificação. Os fragmentos a seguir, com o verbo de cognição decidir, exemplificam isso:

(1) Segundo ela, chega uma idade em que o jovem tem que decidir se continua a morar com os pais tendo como futuro ser um agricultor ou se vai para uma cidade mais desenvolvida tentar estudar e trabalhar. (Corpus D\&G/ Natal, p. 74) 
(2) ... porque ... eu pelo menos eu assim ... se eu decidir uma coisa vou até o fim ... eu não digo que tá errado não ... (Corpus D\&G/Natal, p. 118)

O fragmento (1) pode ser considerado cognitivamente mais complexo porque apresenta uma cena em que uma decisão deve ser tomada a partir da colocação das duas possibilidades de escolha. Observe-se que esse fragmento traz também uma maior complexidade estrutural, com o uso de mais material linguístico e de complemento oracional introduzido por uma conjunção (트), que marca aquilo que se apresenta como possibilidade. No fragmento (2), por outro lado, a complexidade cognitiva parece menor, pois o verbo decidir não foi usado para expressar uma tomada de decisão, mas apenas com o intuito de caracterizar a pessoa que fala. Neste segundo caso, verifica-se que o complemento do verbo é apenas um SN curto, cujo núcleo, a palavra coisa, reforça o sentido genérico expresso pelo enunciado.

O subprincípio da proximidade prediz que a maior aproximação entre os elementos da estrutura morfossintática é reflexo de uma maior integração entre os conceitos que eles suscitam, enquanto o da ordenação linear se manifesta no fato de que o tópico da informação tende a vir em primeiro lugar (GIVÓN, 1984). Este último subprincípio encontra-se exemplificado no fragmento (3), em que parte do complemento do verbo achar é antecipado por assumir o papel de tópico1:

(3) é ... os jogadores eu acho que ... a seleção ... não foi bem convocada né ... eu acho que ... os jogadores estrangeiros ... é que são considerados ... os que jogam fora ... os brasileiros que jogam fora na Europa ... não deveriam ser convocados po/ pois tem ... o Brasil tem grandes jogadores aqui dentro ... né ... (Corpus D\&G/Natal, p. 12)

${ }^{1}$ É importante destacar que o subprincípio da ordenação linear opera sobre o SN "os jogadores", que tem estatuto de tópico, e não sobre o conteúdo do complemento oracional do verbo "achar" (que ... a seleção ... não foi bem convocada).

${ }^{2}$ Em inglês, Usage-Based Linguistics.

Segundo Bybee (2010), a teoria centrada no uso², também chamada Linguística Cognitivo-Funcional, desenvolveu-se diretamente do funcionalismo americano e é quase um novo nome para ele. Essa teoria é, de acordo com Martelotta (2011, p. 55-56), um tipo de abordagem que "considera haver uma relação estreita entre a estrutura das línguas e o uso que os falantes fazem delas nos contextos reais de comunicação". 
Martelotta (2010, p. 62-63) explica que o termo cognitivofuncional está sendo usado "para designar um conjunto de propostas teórico-metodológicas que caracterizam algumas escolas de natureza relativamente distinta, que, adotando princípios distintos dos que caracterizam o formalismo gerativista, apresentam alguns pontos em comum", tais como: a observação do uso da língua, não apenas no nível da frase, mas, sobretudo, do texto e do diálogo; a consideração de que a linguagem é reflexo de um conjunto de atividades comunicativas, sociais e cognitivas; a visão de que a língua é dinâmica, permitindo ao falante adaptar as estruturas linguísticas aos diferentes contextos de comunicação. Dada essa possibilidade de generalização que o termo cognitivofuncional oferece, os pesquisadores brasileiros do Grupo de Estudos Discurso \& Gramática, cujos trabalhos têm como suporte esse novo modelo teórico-metodológico, decidiram recentemente designá-lo com o termo Linguística Funcional Centrada no Uso (LFCU), a fim de melhor se identificarem e marcarem sua origem (cf. FURTADO DA CUNHA; BISPO; SILVA, 2013). Também recente é a introdução de questões referentes à gramática de construções e ao ensino de língua materna na agenda de investigações da LFCU.

Esse novo modelo absorve princípios, processos e categorias integrantes da linguística funcional norte-americana e da linguística cognitiva, dentre os quais serão agora expostos os que se mostram relevantes para o desenvolvimento deste trabalho.

No âmbito dos estudos da linguística funcional norteamericana, além do princípio da iconicidade, os conceitos de marcação e informatividade já eram largamente utilizados e, agora, assim também ocorre no da LFCU. A marcação consiste na indicação, entre categorias correspondentes, de qual é marcada e qual é não marcada, conforme os critérios de complexidade cognitiva, complexidade estrutural e frequência (GIVÓN, 1990). A complexidade cognitiva indica como marcada a categoria que demanda maior esforço mental, atenção ou tempo de processamento; a complexidade estrutural coloca como marcada a estrutura maior e a distribuição de frequência revela que a categoria marcada tende a ser menos frequente nos textos e, por isso, mais perceptível cognitivamente. 
Furtado da Cunha e Bispo (2013) destacam que a marcação não deve, no entanto, ser tomada como uma relação binária (marcada x não marcada), mas gradiente. Considerando o critério de frequência em relação ao tipo de complemento do verbo de cognição, conforme o Quadro 2, o objeto direto pode ser codificado como OD OR IND (objeto oracional com verbo no indicativo), como em (4), ou OD OR SUBJ (objeto oracional com verbo no subjuntivo), como em (5). O primeiro é o mais frequente e, portanto, o menos marcado, ao passo que o segundo é o menos frequente e, portanto, o mais marcado. Com base nos resultados deste estudo preliminar, é possível afirmar que, em relação a esse critério e a partir do padrão mais marcado S - V - OD OR SUBJ, as configurações S - V - OD OR INF e $S$ - V - OD DEM são menos marcadas, assim como o padrão $S$ - V - OD SN é menos marcado que estes dois últimos. A configuração $S$ - V - OD ANAF/INF é ainda menos marcada que o anterior, porém mais marcada que $S-V-O D$ OR IND, que é o menos marcado de todos os padrões identificados, dada a sua frequência mais alta. Há, portanto, escalaridade entre as possibilidades de codificação do complemento dos verbos de cognição, no que diz respeito ao critério de marcação.

(4) ... aí ele imaginou logo que tavam esperando eles mesmo... né?... ${ }^{3}$

(5) ... mas eu num acho que... essa seleção seja... a seleção...

A informatividade diz respeito tanto à quantidade de informação que o locutor utiliza na composição da mensagem, conforme sua consideração do que o interlocutor conhece ou não, quanto ao monitoramento, pelo locutor, do ponto de vista do interlocutor, a fim de atingir determinado objetivo.

A linguística cognitiva dá sua contribuição principalmente com dois processos cognitivos que são considerados essenciais para a LFCU: a categorização e a metáfora.

A categorização é entendida como "o processo através

${ }^{3}$ Os exemplos aqui utilizados sem a indicação da fonte foram retirados da entrevista que forneceu os dados para este estudo. do qual agrupamos entidades semelhantes (objetos, pessoas, lugares etc.) em classes específicas" (FERRARI, 2011, p. 31). Não se trata, no entanto, do rígido modelo clássico de categorização. Para a linguística cognitiva, cada elemento de uma categoria mantém alguns traços em comum com os demais, mas não 
necessariamente todos os traços. As categorias "são ancoradas em protótipos conceptualmente salientes, que desempenham papel crucial na formação dessas categorias" (FERRARI, 2011, p. 39). Concebe-se, assim, uma escala de prototipicidade, constituída de um contínuo no qual membros intermediários se colocam entre os protótipos ou seus similares, que são os representantes mais centrais da categoria, e os representantes mais periféricos, que guardam poucos traços em comum com o núcleo da categoria. É este processo que permite, por exemplo, identificar os verbos de processos mentais e seus subtipos, assim como, num trabalho como este, reconhecer nos dados analisados os verbos de cognição, a partir da consideração do processo mental que eles expressam, que é um traço que esses verbos têm em comum.

O segundo processo cognitivo, a metáfora, não se relaciona, aqui, à figura de linguagem. Na LFCU, a metáfora é um processo cognitivo pelo qual um elemento tem seu significado ampliado, partindo de um sentido mais concreto (comumente espacial) para outro menos concreto, descrevendo uma trajetória de abstratização semântica. Essa ampliação de sentido não é aleatória, mas motivada por analogia e afinidade, de modo que um domínio conceptual é associado a outro (HOPPER e TRAUGOTT, 2003). Nesse sentido, Votre (1996, p. 32) chega a concluir que "a linguagem usual é essencialmente metafórica, no sentido de que quase nunca se criam novas formas, mas novos significados estão sendo continuamente criados para as formas já disponíveis na língua". Entre os verbos de cognição, achar se apresenta como exemplo para o fenômeno da metáfora, pois parte de um sentido de localização espacial (como sinônimo de encontrar) para agora expressar a ideia de consideração, como se vê em (6).

(6) Esses encontro é um encontro... eu acho... assim... verdadeiramente evangélico, sabe?...

\subsubsection{A transitividade verbal no contexto da LFCU}

A linguística funcional norte-americana desenvolveu uma análise aprofundada sobre a transitividade, na qual se baseiam os estudos da LFCU sobre esse tema. Ao contrário do que ocorre nas gramáticas tradicionais, que tratam confusamente a regência e a transitividade verbal, colocando- 
as praticamente como sinônimas, no contexto da linguística funcional esses conceitos encontram-se bem delimitados. Furtado da Cunha e Souza (2011, p. 31) explicam que a "regência verbal é a relação de dependência que se dá entre um termo regente (verbo) e um termo regido (complemento). A regência é um fenômeno formal que apenas informa se o verbo pede um objeto (direto ou indireto)". Sobre a transitividade, as autoras expõem que "em seu sentido original, denota a transferência de uma atividade de um agente para um paciente" (FURTADO DA CUNHA; SOUZA, 2011, p. 31). Enquanto na gramática tradicional a transitividade é colocada como propriedade do verbo, a linguística funcional deixa evidente que ela diz respeito à gramática da oração, pois se manifesta nas relações estabelecidas entre o verbo e seus argumentos. Nas palavras de Furtado da Cunha e Souza (2011, p. 37):

Segundo esse modelo teórico, o fenômeno da transitividade apresenta um componente semântico e um componente sintático. Uma oração transitiva descreve um evento que potencialmente envolve pelo menos dois participantes, um agente que é responsável pela ação, codificado sintaticamente como sujeito, e um paciente que é afetado por essa ação, codificado sintaticamente como objeto direto. Esses participantes são chamados de argumentos do verbo.

É importante ressaltar que essa caracterização remete à oração transitiva prototípica, mas que a LFCU considera também como transitivas outras orações que se afastam, em maior ou menor intensidade, desse núcleo.

Nesse quadro teórico-metodológico, adotam-se duas propostas de análise da transitividade. Uma, elaborada por Givón (2001), analisa a transitividade conforme a caracterização semântica do agente, do paciente e do verbo. A outra, de Hopper e Thompson (1980), analisa a transitividade a partir de dez parâmetros sintático-semânticos, usados para avaliar se a oração apresenta alta ou baixa transitividade. A oração transitiva prototípica é a que apresenta todos os traços avaliados positivamente. Furtado da Cunha (2008) amplia esta última proposta, pois considera a transitividade também nos casos em que o objeto direto não está expresso, havendo apenas um argumento sintaticamente ligado ao verbo.

O fundamental é que, para a LFCU, o fenômeno da transitividade não é dicotômico, como exposto pela gramática 
tradicional (transitivo $x$ intransitivo), mas gradiente. Isso implica dizer que, no discurso, os usuários da língua produzem grande número de orações transitivas conforme caracterizado por Furtado da Cunha e Souza (2011), mas também outras que podem se afastar, em menor ou maior grau, desse protótipo, por exemplo, por apresentarem um objeto direto que não desempenhe o papel semântico de paciente - como no caso de orações com verbos de cognição (como entender e aprender), em que o objeto não sofre nenhum afetamento (mudança de estado ou de localização) -, ou por não apresentarem um objeto expresso - seja porque o objeto já foi dado ou é recuperável pelo contexto (objeto anafórico), seja porque é pragmaticamente irrelevante e não pode ser recuperado com precisão (objeto inferido) (FURTADO DA CUNHA, 2008). Mesmo assim, pelo processo cognitivo da metáfora, essas orações, que não estão no centro da categoria de transitivas, são também analisadas como tal.

\subsection{A Gramática de Construções e as construções} de estrutura argumental

Paradigma elaborado por Fillmore e colaboradores e, depois, por Kay e Fillmore, a gramática de construções tem como base a correspondência entre forma e significado, proposta para todas as expressões linguísticas, desde as mais simples até as mais complexas (FERRARI, 2011). Goldberg (1995) adota esse paradigma e define uma construção gramatical como um par forma-significado.

Mais recentemente, Traugott e Trousdale (2013) explicam que as construções são esquemas linguísticos abstratos, semanticamente gerais, identificados através de um processo indutivo, uma vez que se parte das realizações (do uso) para as generalizações, ou seja, parte-se dos construtos (instanciações específicas utilizadas no discurso) para a identificação de subesquemas, os quais, por sua vez, permitem a identificação dos esquemas, que são mais gerais. Isso só é possível através do processo de categorização, que possibilita relacionar elementos com traços semelhantes e agrupá-los sob um mesmo (sub) esquema. Por exemplo, uma oração como "vamo conhecer Fortaleza" é uma instanciação de oração transitiva com verbo de cognição (SUJEITO - VERBO DE COGNIÇÃO - OBJETO 
DIRETO) e esta, por sua vez, é um subesquema do esquema oração transitiva (SUJEITO - VERBO - OBJETO DIRETO).

$\mathrm{O}$ termo estrutura argumental (EA) se refere, de um modo geral, conforme explanado em Furtado da Cunha (2006), ao conjunto de relações estabelecidas entre um predicado (um verbo, neste trabalho) e seus argumentos. Essas relações se manifestam em diferentes níveis linguísticos. De uma perspectiva sintática, a estrutura argumental especifica o número e as relações gramaticais (sujeito, objeto direto etc.) dos argumentos de um predicado. De uma perspectiva semântica, focaliza os papéis semânticos (agente, paciente etc.) que são atribuídos aos argumentos de um predicado. De uma perspectiva cognitiva, codifica cenas que são fundamentais à experiência humana, isto é, reflete uma estrutura de expectativas desencadeadas pelo verbo. Por último, de uma perspectiva pragmática, descreve os diferentes modos em que essencialmente a mesma informação, ou o mesmo conteúdo semântico-proposicional, pode ser estruturada a fim de refletir seu status informacional.

Pode-se afirmar, portanto, que a estrutura argumental relaciona a sintaxe, a semântica e a pragmática, haja vista que implica a noção da exigência de determinados termos para preencher a valência do verbo, mas considera que há restrições semânticas para esse preenchimento e que a realização efetiva da construção resulta de necessidades e intenções comunicativas (NEVES, 2006).

Quanto às construções de estrutura argumental, Goldberg (1995, p. 3) as define como "uma subclasse especial de construções que fornece os meios básicos de expressão oracional em uma língua". Segundo ela, as construções de estrutura argumental correspondem a sentenças ordinárias, constituídas por um verbo e seus argumentos, cuja análise considera tanto os papéis argumentais, associados à construção, quanto os papéis participantes, ligados ao verbo, pois se admite que o sentido global da construção é dado pela associação do significado da construção com o significado dos itens lexicais que a compõem. 


\section{Coleta dos Dados}

Os dados utilizados neste estudo foram coletados a partir da audição da entrevista sociolinguística gravada com um homem representante da fala de Natal/RN, de 50 anos, com nível de escolaridade de Ensino Fundamental II. Em atenção aos estudos sobre o fenômeno da transitividade, foram consideradas as orações simples ou principais, ativas e declarativas (afirmativas ou negativas). Os trechos da entrevista que apresentavam orações com verbos de cognição e atendiam a esses requisitos foram transcritos para favorecer a tabulação dos dados e a análise. Ao todo, foram identificadas 74 ocorrências de orações com verbos de cognição. A fim de assegurar a não-identificação do informante, o seu nome e o de outras pessoas do seu círculo de relacionamento que foram mencionadas durante a entrevista foram identificados, nos trechos transcritos, apenas pelas iniciais. Nomes de pessoas públicas foram mantidos.

\section{Resultados e análise dos dados}

Nesta seção, apresentam-se os resultados do estudo empreendido, os quais servem à análise preliminar a respeito da construção de estrutura argumental com verbos de cognição no português brasileiro. Os dados serão analisados de forma essencialmente qualitativa, mas com suporte quantitativo, enquanto evidenciador de tendências, em relação ao objetivo geral e aos objetivos específicos.

Conforme exposto na primeira seção, os verbos de cognição indicam processos mentais relacionados à decisão, à consideração ou à crença, à memória, à compreensão e ao planejamento. No caso dos dados coletados para este trabalho, esses processos foram expressos por treze verbos: achar, imaginar, acreditar, confiar, conhecer, pensar, descobrir, saber, aprender, estudar, lembrar, esquecer e programar. O Quadro 1 , a seguir, agrupa esses verbos pelo sentido que expressam e informa o número de ocorrências de cada um deles (entre parênteses) além das ocorrências para cada sentido, em números absolutos e em percentual. 
Quadro 1 - Ocorrências dos verbos de cognição

\begin{tabular}{|c|c|c|c|}
\hline Sentido & Verbos & $\mathbf{N}^{\mathbf{0}}$ ocor. & Perc. \\
\hline Consideração/crença & $\begin{array}{c}\text { achar (21), acreditar (9), } \\
\text { confiar (1), imaginar (1) }\end{array}$ & 32 & $43,24 \%$ \\
\hline $\begin{array}{c}\text { Compreensão/ } \\
\text { conhecimento }\end{array}$ & $\begin{array}{c}\text { saber (15), conhecer (7), } \\
\text { estudar (5), pensar (4), } \\
\text { descobrir (1), aprender (1) }\end{array}$ & 33 & $44,60 \%$ \\
\hline Memória & lembrar (5), esquecer (1) & 6 & $8,11 \%$ \\
\hline Planejamento & Total & $\mathbf{7 4}$ & $\mathbf{3}, 05 \%$ \\
\hline \multirow{2}{*}{} & \multicolumn{2}{c|}{} &
\end{tabular}

Observe-se que, entre as 74 ocorrências levantadas, não há verbos que expressem o sentido de decisão. Os sentidos mais recorrentes foram os de consideração/crença e de compreensão/conhecimento, que apresentam praticamente os mesmos resultados e representam, juntos, quase $90 \%$ do total de dados, enquanto o menos frequente foi o de planejamento. Talvez porque este sentido, assim como o de decisão, seja cognitivamente mais complexo e por isso não guarde estreita relação com a natureza pessoal e informal do material pesquisado, ao contrário dos verbos que expressam processos ligados à consideração/crença e à compreensão/conhecimento, que parecem bem afinados com a intenção comunicativa da entrevista, que era a de que o informante falasse sobre si e sobre sua vida.

Quanto aos padrões oracionais identificados, a estrutura sintática formada por sujeito, verbo de cognição e objeto direto ( $\mathrm{S}-\mathrm{V}$ - OD) foi verificada na grande maioria das ocorrências, conforme se observa no Quadro 2. 
Quadro 2 - Padrões oracionais com verbos de cognição

\begin{tabular}{|c|c|c|c|c|c|}
\hline & \multicolumn{2}{|c|}{ Padrões } & \multirow{2}{*}{$\begin{array}{c}\text { Ocorr. } \\
33\end{array}$} & \multirow{2}{*}{$\begin{array}{c}\% \\
44,60 \%\end{array}$} & \multirow{2}{*}{$\begin{array}{l}\text { Dados } \\
\text { “... lá em casa... eu acredito que } \\
\text { ninguém teve infância... né?..." }\end{array}$} \\
\hline \multirow{7}{*}{1} & \multirow{7}{*}{$S-V-O D$} & $\begin{array}{l}\mathrm{S}-\mathrm{V}- \\
\text { OD OR IND }\end{array}$ & & & \\
\hline & & $\begin{array}{l}\text { S - V - OD } \\
\text { ANAF/INFER }\end{array}$ & 20 & $27,02 \%$ & $\begin{array}{l}\text { “... ela cheirou minha boca... ‘Tava fumando, } \\
\text { caba safado!'... pufo na minha boca... só deu } \\
\text { essa vez... nunca mais mãe bateu... só deu } \\
\text { essa vez... mas você... eu nunca esqueci...” }\end{array}$ \\
\hline & & $S-V-O D S N$ & 8 & $10,81 \%$ & $\begin{array}{l}\text { "... acompanho futebol há muito tempo... e... } \\
\text { eu conheço alguma coisa de futebol..." }\end{array}$ \\
\hline & & S - V - OD DEM & 4 & $5,40 \%$ & $\begin{array}{l}\text { "... pronto... eu trabalhava na secretaria } \\
\text { de educação... aí as pessoas ficavam } \\
\text { sabendo o que é que eu fazia..." }\end{array}$ \\
\hline & & $\begin{array}{l}\mathrm{S}-\mathrm{V}- \\
\mathrm{OD} \text { OR INF }\end{array}$ & 4 & $5,40 \%$ & $\begin{array}{l}\text { “... eu num penso muito... sair daqui pra São Paulo } \\
\underline{\text { de avião... pra mim é uma viagem sem graça..." }}\end{array}$ \\
\hline & & $\begin{array}{l}\mathrm{S}-\mathrm{V}- \\
\text { OD OR SUBJ }\end{array}$ & 2 & $2,70 \%$ & $\begin{array}{l}\text { "... esses aí num escaparam bem de verdade } \\
\text { porque... pronto... } \mathrm{S} \text { eu acho que ele talvez tivesse } \\
\text { uns doze... talvez num tivesse quinze anos ainda } \\
\text { quando papai botou pra trabalhar com P..." }\end{array}$ \\
\hline & & Subtotal & 71 & $95,95 \%$ & \\
\hline 2 & $\begin{array}{l}S-V-O D \\
-P R E D\end{array}$ & $\begin{array}{l}S-V- \\
\text { OD (ANAF) } \\
- \text { PRED }\end{array}$ & 2 & $2,70 \%$ & $\begin{array}{l}\text { ".. muita gente... às vezes... até sai de uma } \\
\text { situação difícil quando escuta um testemunho } \\
\text { desse... né?... aí... eu acho muito bom... é } \\
\text { pu... é puramente é... evangélico memo... } \\
\text { coisa de... diretamente da igreja..." }\end{array}$ \\
\hline \multirow[t]{2}{*}{3} & \multicolumn{2}{|c|}{$S-V-C$ REL } & 1 & $1,35 \%$ & $\begin{array}{l}\text { "... Neymar é aquela estrela que... a estrela que } \\
\text { fica brilhando e apagando... num é... o... eu } \\
\text { num acredito nele ainda de verdade... né?..." }\end{array}$ \\
\hline & \multicolumn{2}{|l|}{ TOTAL } & 74 & $100 \%$ & \\
\hline
\end{tabular}

Já se expôs anteriormente que a construção de estrutura argumental para os verbos de cognição corresponde a um subesquema da construção transitiva. Observe-se, pelo Quadro 2, que o padrão mais frequente nos dados analisados é, de fato, o da estrutura SUJEITO - VERBO DE COGNIÇÃO OBJETO DIRETO (S - V - OD), que parece ser a prototípica para os verbos de cognição, dada sua alta frequência. Na oração transitiva prototípica, há um sujeito que é agente de uma ação, expressa pelo verbo, a qual afeta um objeto direto, que é paciente. A estrutura predominante com os verbos de cognição identificados apresenta, portanto, uma correspondência sintática com o esquema da oração transitiva prototípica, em que o verbo é acompanhado de dois argumentos: o sujeito e o objeto direto. Apesar disso, a construção que corresponde a orações com verbo de cognição é considerada subesquema da oração transitiva porque é menos generalizante que esta, já que o verbo é, necessariamente, um verbo do tipo de cognição. Semanticamente, as diferenças são maiores, haja vista que o verbo de cognição não expressa ação, mas atividade mental. Portanto, nesse caso, o sujeito não desempenha o papel de 
agente, mas de experienciador, e é prototipicamente humano, embora possa, em orações construídas metaforicamente, estar representado por seres sem consciência, o que não se verificou nos dados aqui analisados; o objeto direto, por sua vez, corresponde ao fenômeno processado na mente do sujeito e também não é afetado, mas experienciado. Essa semelhança sintática com semântica diferente é indicativa de que a construção de estrutura argumental com verbo de cognição é uma extensão da construção transitiva prototípica, o que é possível pelo estabelecimento entre elas de um tipo de relação entre construções que Traugott e Trousdale (2013) nomeiam de polissemia, a qual se verifica quando as construções têm especificações sintáticas idênticas, mas são distintas semanticamente.

Note-se que, desse subesquema de oração com verbo de cognição, derivam outros ainda mais específicos. A diferença entre estes, no entanto, advém apenas da natureza morfossintática do elemento linguístico que assume a função de objeto direto, sendo mais frequentes ocorrências em que uma oração subordinada com verbo flexionado no modo indicativo (S - V - OD OR IND) assume essa função, subesquema instanciado em quase $45 \%$ do total de ocorrências contra pouco mais de $10 \%$ de construtos com sintagma nominal funcionando como objeto (S - V - OD SN), o que é comum na oração transitiva prototípica. A maior frequência da oração no indicativo como complemento deve estar relacionada ao subprincípio da quantidade, segundo o qual quanto mais complexa for a mensagem, maior será a quantidade de forma necessária para sua codificação, já que os verbos de cognição expressam um processo mental, portanto envolvem abstração e, consequentemente, maior complexidade cognitiva que a imposta por um verbo que expressa uma ação que afeta um objeto.

Também teve uso significativo a oração com o objeto direto não expresso, nas situações em que ele é anafórico ou inferido ( $\mathrm{S}$ - V - OD ANAF/INFER), como na ocorrência constante no Quadro 2, em que o objeto do verbo esquecer não está expresso na oração, mas pode ser recuperado pelo contexto. Nos dados coletados, esse tipo de objeto ocorre em três situações: quando é facilmente recuperável pelo contexto, como no dado comentado; quando o verbo é empregado em um sentido mais genérico, como em (7), em que o objeto 
é pragmaticamente irrelevante e não pode ser recuperado com precisão, mas é possível inferir que o informante se refere àquilo que é necessário saber para realizar o trabalho; quando o objeto é antecipado, por ser uma informação que se deseja destacar, de acordo com o subprincípio da ordenação linear, como se vê em (8), com o verbo achar, que tem como complemento uma oração no indicativo (OD OR IND): “eu já fui em Fortaleza".

(7) ... isso é de trabalho... e trabalhar você ganha dinheiro assim... você vai... conhece... faz o serviço e ganha o dinheiro... ninguém acha o dinheiro.

(8) ... eu já fui em Fortaleza eu acho que umas... três vezes... foi...

Também foram encontradas realizações de outros três subesquemas, que se mostraram pouco produtivos, dada a baixa frequência com que ocorreram: o que tem como objeto direto o pronome demonstrativo $\underline{\mathrm{o}}$, equivalente a aquilo, sempre seguido de uma oração adjetiva (S - V - OD DEM); o que tem como complemento uma oração subordinada reduzida, não introduzida por conjunção e com verbo no infinitivo, (S - V - OD OR INF); e o que tem como objeto uma cláusula com o verbo flexionado no modo subjuntivo ( $\mathrm{S}-\mathrm{V}$ - OD OR SUBJ), a qual, nos dados aqui utilizados, foi usada em situações de dúvida.

Além da construção prototípica (S - V - OD), outros dois padrões foram utilizados para expressar cognição, mas eles somam apenas 4,05\% das ocorrências. E, mesmo assim, um deles ainda guarda estreita relação com a construção prototípica, funcionando como uma espécie de extensão dela. É o que se verifica no padrão formado por sujeito, verbo de cognição, objeto direto e predicativo (S - V - OD (ANAF) - PRED), no qual se vê a estrutura prototípica adicionada de predicativo. Nos dados analisados, foram encontradas apenas duas instanciações desse padrão, ambas com o verbo achar, que expressa o sentido de consideração. Esse sentido se assemelha, nesses dois casos, a um sentido de julgamento, que é feito sobre o objeto e marcado através do predicativo. Nas duas ocorrências encontradas, o objeto direto é anafórico, mas os dados não são suficientes para indicar que essa seja uma 
tendência, por isso o termo anafórico (ANAF) foi colocado entre parênteses no subesquema.

$\mathrm{Na}$ verdade, mesmo o padrão formado por sujeito, verbo de cognição e complemento relativo (S - V - C REL), que teve apenas uma realização nos dados aqui analisados, pode ser assimilado pela construção prototípica ( $\mathrm{S}-\mathrm{V}-\mathrm{OD})$, já que o complemento relativo é aquele introduzido por uma preposição que é, na verdade, uma extensão do verbo e indica, segundo Bechara (2009), uma relação de servidão gramatical, no sentido de que cada verbo se acompanha de sua própria preposição. Sendo assim, se a preposição integra o verbo, e não o complemento relativo, é possível dizer que este tem um comportamento semelhante ao do objeto direto.

\section{Considerações finais}

Os dados coletados para a realização deste estudo revelaram o uso de treze diferentes verbos para expressar processos mentais de cognição: achar imaginar, acreditar, confiar, conhecer, pensar, descobrir saber, aprender, estudar, lembrar, esquecer e programar.

Os resultados obtidos e a análise desenvolvida na seção anterior demonstram que a construção de estrutura argumental prototípica para os verbos de cognição é a que se representa por $S$ - V - OD, a qual é, na verdade, um subesquema da construção transitiva prototípica, uma vez que é formada, assim como esta, pelo verbo e dois argumentos, um que desempenha o papel de sujeito e outro que desempenha o papel de objeto direto, mas é menos esquemática que a transitiva prototípica, já que o verbo é, necessariamente, do tipo de cognição. Pode-se dizer que há, entre a construção transitiva prototípica e a construção de estrutura argumental com verbos de cognição, uma relação de polissemia, já que essas construções têm especificações sintáticas idênticas, mas são distintas semanticamente: na oração transitiva prototípica, o sujeito é agente, o verbo é de ação e o objeto é afetado; na oração com verbo de cognição, o sujeito é experienciador, o verbo indica um processo mental e o objeto corresponde ao fenômeno que é experienciado na mente do sujeito.

Esse padrão prototípico para as orações com verbos de cognição (S - V - OD) é instanciado em 95,95\% dos construtos, 
os quais remetem a subesquemas mais específicos, derivados do padrão prototípico. A especificidade, nesse caso, diz respeito ao item linguístico que assume a função de objeto direto, a qual pode ser desempenhada por uma oração no indicativo (OD OR IND), por um objeto não-expresso, anafórico ou inferido (OD ANAF/INFER), por um sintagma nominal (OD SN), por um pronome demonstrativo (OD DEM), por uma cláusula no infinitivo (OD OR INF) ou por uma cláusula no subjuntivo (OD OR SUBJ). Dentre esses subesquemas mais específicos, os três primeiros são realizados em um percentual maior de ocorrências: $44,60 \%, 27,02 \%$ e 10,81\%, respectivamente, enquanto os três últimos são realizados em um percentual bem menor de ocorrências: 5,40\%, 5,40\% e 2,70\%, respectivamente. É possível que essa diferença no número de instanciações destes últimos subesquemas se justifique pelo fato de que esses três padrões são sintática e semanticamente mais complexos, portanto mais marcados e, consequentemente, menos frequentes: o pronome demonstrativo é seguido de uma oração adjetiva; pelo princípio da quantidade e da proximidade, a cláusula no infinitivo pode ser considerada menos complexa que a oração desenvolvida, porém, com relação à frequência, a oração no modo indicativo é, na amostra examinada, a menos marcada, já que o padrão com esse tipo de complemento apresentou o maior número de ocorrências, quase $45 \%$ do total, com larga vantagem sobre as demais possibilidades de complemento para os verbos de cognição; a cláusula no subjuntivo também pressupõe um predicado complexo, com flexão em um modo verbal menos usual e parece ainda limitada pela circunstância de uso, ou seja, a expressão de dúvida. Além disso, esses subesquemas mais complexos acabam por parecerem menos adequados ao caráter pessoal e informal da entrevista.

Os dados revelaram outros dois padrões utilizados para expressar cognição, mas eles são instanciados em apenas $4,05 \%$ das ocorrências. E, mesmo assim, um deles, o padrão formado por sujeito, verbo de cognição, objeto direto e predicativo (S - V - OD (ANAF) - PRED), funciona como uma espécie de extensão da construção prototípica, com a adição do predicativo. O outro padrão, formado por sujeito, verbo de cognição e complemento relativo ( $\mathrm{S}-\mathrm{V}-\mathrm{C}$ REL), pode, por sua vez, ser assimilado pela construção prototípica, já que o 
complemento relativo tem um comportamento semelhante ao do objeto direto.

A limitação deste estudo, que utilizou dados de um único informante e apenas de língua falada, não permite fazer generalizações. No entanto, é possível afirmar que os dados analisados sugerem fortemente que há uma construção de estrutura argumental prototípica para os verbos de cognição no português brasileiro, a qual parece se manifestar na grande maioria dos construtos. As principais variações ocorrem entre subesquemas dela derivados e dizem respeito ao elemento linguístico que ocupa a função de objeto direto. $\mathrm{E}$, de qualquer modo, este estudo pode ser interpretado como um evidenciador de tendências que podem se confirmar na pesquisa de doutorado que se encontra, ainda, em fase inicial.

\section{REFERÊNCIAS}

BECHARA, E. Moderna gramática portuguesa. 37. ed. rev. amp. e atual. Rio de Janeiro: Nova Fronteira, 2009.

BYBEE, J. Language as a complex adaptative system: the interaction of cognition, culture and use. In: usage and cognition. Cambridge: CUP, 2010. p. 194-221. Language, FERRARI, L. Introdução à linguística cognitiva. São Paulo: Contexto, 2011.

FORD, C. E. et al. Social interaction and grammar. In: TOMASELLO, M. (Ed.). The new psychology of language: cognitive and functional approaches to language structure. v. 2. Mahwah, NJ/London: LEA, 2003, p. 119-143.

FURTADO DA CUNHA, M. A. Estrutura argumental e valência: a relação gramatical objeto direto. Gragoatá, n. 21, p. 115-131, 2006.

O objeto zero de verbos transitivos. Linguística (PPGL/ UFRJ), v. 4, p. 59-76, 2008.

FURTADODA CUNHA, M. A.; SOUZA, M. M. de. Transitividade e seus contextos de uso. São Paulo: Cortez, 2011. (Coleção Leituras introdutórias em linguagem, v. 2).

FURTADO DA CUNHA, M. A.; BISPO, E. B. Pressupostos teórico-metodológicos e categorias analíticas da Linguística Funcional Centrada no Uso. Revista do GELNE, v. 15, p. 49-74, 2013. 
FURTADO DA CUNHA, M. A.; BISPO, E. B.; SILVA, J. R. Linguística funcional centrada no uso: conceitos básicos e categorias analíticas. In: CEZARIO, M. M.;

FURTADO DA CUNHA, M. A. (orgs.) Linguística centrada no uso: uma homenagem a Mário Martelotta. Rio de Janeiro/ Cataguases-MG: Mauad X/ FAPERJ (2013).

GIVÓN, T. Syntax: a functional-typological introduction. v. 1. New York: Academic Press, 1984.

. Function, structure, and language acquisition. In: SLOBIN, D. (Ed.). The crosslinguistic study of language acquisition. v. 2. Hillsdale: Lawrence Erlbaum, 1985. p. 1005-1028.

Syntax: a functional-typological introduction. v. 2. Philadelphia: John Benjamins, 1990.

Functionalism and grammar. Amsterdam/Philadelphia: John Benjamins, 1995.

Syntax: an introduction. v. 1 e 2. Amsterdam/ Philadelphia: John Benjamins, 2001.

GOLDBERG, A. E. A construction grammar approach to argument structure. Chicago: University of Chicago Press, 1995.

GOUVEIA, C. A. M. Texto e gramática: uma introdução à linguística sistêmico-funcional. Matraga, n 24, p. 13-47, jan./jun. 2009. Disponível em: <http://ww3.fl.ul.pt/pessoais/cgouveia/ ja/6.pdf>. Acesso em: 17 set. 2012.

HAIMAN, J. Natural syntax: iconicity and erosion. Cambridge: Cambridge University Press, 1985.

HALLIDAY, M. A. K. An introduction to functional grammar. London: Edward Arnold, 1985.

HALLIDAY, M. A. K.; MATTHIESSEN, C. M. I. M. Introduction to functional grammar. 3. ed. London: Edward Arnold, 2004.

HOPPER, P. J. Emergent grammar. In: TOMASELLO, M. (Ed.). The new psychology of language. New Jersey: Lawrence Erlbaum, 1998, p. 155-175.

HOPPER, P. J.; THOMPSON, S. A. Transitivity in grammar and discourse. Language, v. 56, p. 251-299, 1980.

HOPPER, P. J.; TRAUGOTT, E. C. Grammaticalization. 2. ed. Cambridge: Cambridge University Press, 2003. 
LEHMANN, C. Thoughts on grammaticalization: a programmatic sketch. v. I. (Arbeiten des Kolner Universalien-Projekts 48) Koln: Universitat zu Koln, Institut fur Sprachwissenschaft, 1982.

MARTELOTTA, M. E. Conceitos de gramática. In: (org.). Manual de linguística. São Paulo: Contexto, 2010. p. 43-70. Mudança linguística: uma abordagem baseada no uso. São Paulo: Cortez, 2011.

NEVES, M. H. de M. Texto e gramática. São Paulo: Contexto, 2006.

SOUZA, M. M. de. Querer, pretender, considerar: os processos mentais no gênero editorial. In: PG LETRAS 30 ANOS, 2006, Recife-PE, UFPE. Anais... v. 1. Recife-PE, 2006. p. 457-469. Disponível em: <http://www.pgletras.com.br/Anais-30-Anos/ Docs/Artigos/4.\%20Dout\%20e\%20mestres\%202006/4.7_Maria_ Medianeira.pdf> Acesso em: 17 set. 2012.

TRAUGOTT, E. C.; TROUSDALE, G. A. A usage-based approach to sign change. In: Constructionalization and constructional changes. Oxford: OUP, 2013.

VOTRE, S. J. Um paradigma para a linguística funcional. In: MARTELOTTA, M. E.; VOTRE, S. J.; CEZARIO, M. M. (Org.). Gramaticalização no português do Brasil: uma abordagem funcional. Rio de Janeiro: Tempo Brasileiro: UFRJ, 1996. 


\section{Abstract \\ The construction with verbs of cognition in Brazilian Portuguese: a preliminary study}

This paper presents a preliminary analysis about the argument structure with cognition verbs in Brazilian Portuguese. Data were collected in a sociolinguistic interview, whose informant is a 50 years old man that represents the speech of Natal/RN and the education level of elementary school. The results show that the prototypical construction of argument structure for the cognition verbs corresponds to a subschema of prototypical transitive construction and it is held in most constructs, which refer to more specific subschemas, depending of the linguistic item which assumes the function of direct object. The theoretical support adopted is the Usage-Based Functional Linguistics, which is a theoretical and methodological model, which follows principles, processes and categories of North American functional linguistics and cognitive linguistics.

Keywords: Argument structure. Cognition verbs. Usage-Based Functional Linguistics. 